\title{
THE D1.1 ANTIGEN: A CELL SURFACE MARKER FOR GERMINAL CELLS OF THE CENTRAL NERVOUS SYSTEM ${ }^{1}$
}

\author{
JOEL M. LEVINE, ${ }^{2}$ LORA BEASLEY, AND WILLIAM B. STALLCUP \\ Molecular Neurobiology Laboratory, The Salk Institute for Biological Studies, San Diego, California 92138
}

Received August 15, 1983; Revised September 21, 1983; Accepted September 21, 1983

\begin{abstract}
A monoclonal antibody against a cell surface ganglioside present on neuroepithelial cells was produced by immunizing mice with the B49 cell line, a clonal line with properties of both neurons and glial cells. The expression of this antigen, designated as D1.1, was analyzed in the developing rat cerebellum.

The D1.1 antigen was localized by the immunofluorescent staining method to germinal cells of the external granule layer (EGL). Fluorescent labeling of cells comprising the EGL was apparent on embryonic day 18 when the EGL first forms, and the labeling was present thorughout the period of postnatal cerebellar development. No cells within the adult cerebellum were labeled with the anti-D1.1 antibody. The D1.1-labeled cells of the EGL synthesize DNA, as demonstrated by $\left[{ }^{3} \mathrm{H}\right]$ thymidine autoradiography. However, within $48 \mathrm{hr}$ after their final mitosis, nascent cerebellar cells that had migrated away from the external granule layer were no longer labeled with antibody. Some of the neurons and some of the astrocytes in cerebellar cell cultures were fluorescently labeled with the anti-D1.1 antibody. The number of anti-D1.1-labeled neurons in the cultures decreased over the first 10 days in vitro in agreement with the findings that in vivo the fluorescent labeling of the D1.1 antigen disappears from postmitotic cells. The antibody recognizes a ganglioside that in thin layer chromatographic experiments has a mobility between that of the $\mathrm{GM}_{1}$ and $\mathrm{GM}_{2}$ ganglioside. These data suggest that the D1.1 ganglioside antigen is a cell surface marker for germinal cells and that the acquisition and subsequent loss of this antigen is an aspect of the biochemical maturation of neurons and glial cells.
\end{abstract}

Most cclls of the mammalian central nervous system (CNS) originate from a specialized region of embryonic ectoderm known as the neuroepithelium. Early in embryogenesis, dorsal ectoderm, under the influence of mesodermal tissues, goes through a series of morphological changes resulting in the formation of the neural plate and neural tube (for review see Jacobson, 1978). The neuroepithelial cells that comprise these structures divide rapidly; their postmitotic daughter cells migrate away from the lumen of the neural tube and differentiate into the neurons and glial cells of the CNS. In other areas of the CNS, such as the cerebellum, a secondary proliferative zone is established. Neuroepithelial cells in the posteroventral margin of the rat cerebellar rudiment begin to migrate dorsally to form the external granule

\footnotetext{
' 'l'his work was supported by a Muscular Dystrophy Association Research Grant, by National Institutes of Health Grant NS 16112 to W. R. S., and by a Muscular Dystrophy Association Fellowship to .J. M. L. We thank Drs. D. Schubert and H. Ingraham for comments on this manuscript.

${ }^{2}$ To whom correspondence should be addressed.
}

layer (EGL) at embryonic day 17 (Altman and Bayer, 1978). Cells of the external granule layer, like the cells comprising the ventricular zones of the developing brain, divide rapidly. Postmitotic daughter cells migrate away from the EGL and differentiate into the inhibitory interneurons of the cerebellar cortex (Altman, 1969, 1972). Although much is known about the time and place of origin of different ncuronal populations (principally through the application of $\left[{ }^{3} \mathrm{H}\right]$ thymidine "birthdating"), the molecular and cellular mechanisms by which neuroepithelial cells generate the diversity and multiplicity of cell types found within the brain remain unknown.

Many of the events of early neurogenesis, such as the control of cell division, cellular migration, and aggregation, are likely to be mediated at least in part by cell surface molecules (Gottlieb and Glaser, 1980). In order to identify and characterize cell surface molecules of the developing brain, we have prepared monoclonal antibodies against the B49 cell line (Schubert et al., 1974). We report here that both B49 cells and neuroepithelial cells express on their surfaces a unique antigenic determinant that is carried on a ganglioside. Using the cerebellum as 
a model system, we show that germinal cells of the EGL express this ganglioside antigen, but postmitotic daughter cells rapidly lose or biochemically alter this surface component so that it is no longer recognized by the monoclonal antibody. Therefore, one aspect of the early development of the CNS is the acquisition and subsequent loss of this cell surface ganglioside antigen. These results suggest that specific gangliosides may play important roles in regulating the early events responsible for the orderly formation of the CNS.

\section{Materials and Methods}

Cell culture. All cell lines were maintained in Dulbecco's modified Eagle's medium (DME) supplemented with $10 \%$ fetal calf serum (FCS, GIBCO). Cultures of postnatal rat cerebellum and embryonic rat brain were prepared and maintained as described (Stallcup, 1981). P3×63Ag8.6.5.3 myeloma cells (Kearney et al., 1979) were grown in DME, supplemented with $10 \%$ FCS and $5 \times 10^{-5} \mathrm{M}$ 2-mercaptoethanol. Prior to use in cell fusion, myeloma cells were grown for 3 days in $10^{-5} \mathrm{M}$ thioguanine.

Hybridoma production and screening. Balb/C, mice were immunized with five weekly intraperitoneal injections of $10^{7} \mathrm{~B} 49$ cells suspended in Dulbecco's phosphatebuffered saline (D-PBS). Four days after the final injection, spleen cells from immunized mice were fused with $10^{8}$ myeloma cells according to Kohler and Milstein (1975). The fusion mixture was washed, resuspended in DME supplemented with $20 \%$ FCS, hypoxanthine, aminopterin, thymidine, and 2-mercaptoethanol, and plated into 1500 microtiter wells (LINBRO, McClean, Va.) over monolayers of murine peritoneal macrophages. After 2 to 3 weeks, wells with visible colonies were screened using the following three-part procedure: supernatants $(100 \mu \mathrm{l})$ were tested for their ability to bind to monolayers of B49 cells using an indirect radioimmune binding assay as described previously (Stallcup and Cohn, 1976). Supernatants from positive wells were then tested by indirect immunofluorescence for their ability to label embryonic rat brain and postnatal rat cerebellar cells in dissociated tissue culture. Finally, positive wells were tested for their ability to label discrete cellular elements in frozen sections of embryonic, postnatal, and adult rat brain as described below. Cells from positive wells were cloned by limiting dilution and again screened as described above.

Immunocytochemistry. Adult and postnatal BDIX rats were perfused intracardially with warm D-PBS followed by a solution of $1 \%$ freshly depolymerized paraformaldehyde (MCB), $0.1 \%$ glutaraldehyde (Sigma), and $0.1 \mathrm{M}$ phosphate buffer, $\mathrm{pH}$ 7.4. Embryos were rapidly removed from timed pregnant Sprague-Dawley rats (Zivic-Miller), rinsed in D-PBS, and fixed by immersion in the same solution at $4^{\circ}$. Following overnight fixation in the same solution containing $20 \%$ sucrose, tissue blocks were frozen in OCT (Fisher) and sectioned at $15 \mu$ using a TissueTek II cyrostat. For immunofluorescence, mounted tissue sections were incubated for $18 \mathrm{hr}$ at $4^{\circ} \mathrm{C}$ with monoclonal antibody-containing tissue culture supernatants diluted $1: 20$ in a solution containing $0.15 \mathrm{M} \mathrm{NaCl}, 20 \mathrm{mM}$ phos- phate, $\mathrm{pH} 7.4,0.5 \%$ Triton X-100 (Rohm and Haas), and $2 \%$ normal goat serum (PBS-Tx-NGS). The slides were washed twice for $10 \mathrm{~min}$ each in PBS-Tx-NGS containing $0.1 \%$ Triton $\mathrm{X}-100$. The binding of the first antibody was detected with a fluorescein-labeled goat anti-mouse IgG and IgM antibody (TAGO, Burlingame, CA) diluted 1:50 in the same solution as the wash buffer. After 30 to $60 \mathrm{~min}$ in a humid atmosphere at room temperature, the slides were washed twice in PBS-NGS, rinsed in distilled water, and mounted in Tris-buffered glycerol, $\mathrm{pH} 8.9$. The sections were examined using a Zeiss microscope equipped for phase and epifluorescent illumination and photographed with a Nikon camera using Kodak Tri-X film. Single and double label fluorescent staining of postnatal rat cerebellar cultures was done as described previously (Stallcup, 1981). The following reagents were used: tetanus toxin (a gift from Dr. R. O. Thomson, Wellcome Laboratories) and rabbit anti-tetanus toxin, rabbit anti-glial fibrillary acidic protein (a gift from Dr. D. Dahl), and rabbit anti-galactocerebroside (a gift from Dr. R. Milner). A rhodamine conjugate of goat antirabbit IgG prepared according to Hartmann (1973) was used in the double label studies.

Autoradiography. Postnatal BDIX rat pups were injected subcutaneously with $\left[{ }^{3} \mathrm{H}\right]$ thymidine (NEN, specific activity $=20 \mathrm{Ci} / \mathrm{mmol}$ ) at a dosage of $10 \mu \mathrm{Ci} / \mathrm{gm}$ of body weight. Following appropriate survival times, the pups were perfused as described above, and tissue sections were prepared for immunocytochemistry. The binding of the first antibody was detected with a horseradish peroxidase conjugate of goat anti-mouse (TAGO) and 3,3'-diaminobenzidine tetrahydrochloride dihydrate (Aldrich). The peroxidase-labeled slides were dipped in N'TB-2 emulsion (Kodak) diluted 1:1 with distilled water and developed after 9 weeks' exposure at $-20^{\circ} \mathrm{C}$. For combined autoradiography and immunofluorescent staining of cerebellar cells in tissue culture, rat pups were injected with $\left[{ }^{3} \mathrm{H}\right]$ thymidine as described above, and, after either 3- or 24-hr survival periods, they were sacrificed and their cerebelli dissociated and plated onto poly-L-lysine-coated glass coverslips. Following immunofluorescent staining of the cultures with tetanus toxin and anti-D1.1, the cultures were fixed in 95\% ethanol, air dried, and dipped in NTB-2 emulsion. After 2 weeks' exposure at $-20^{\circ} \mathrm{C}$, the slides were developed and examined. Between 100 and 150 silver grain-labeled cells were counted for each time point.

Ganglioside preparation. Cell lines grown in glass roller bottles were harvested in EDTA. Gangliosides and other upper phase lipids were extracted from the cell pellets and from tissue samples according to Folch et al. (1957). Gangliosides were also prepared from cell lines grown in $100-\mathrm{mm}$ tissue culture dishes using the procedures of Dahms and Schnarr (1983). In some experiments gangliosides were further purified by DEAE-Sephadex A25 chromatography (Ledeen and $\mathrm{Yu}, 1978$ ) and by Iatro bead chromatography (Momoi et al., 1976). Radioimmune binding to gangliosides separated on plastic-backed high performance thin layer chromatography plates (EM, Merck) in a solvent of chloroform: methanol: water containing 0.02\% $\mathrm{CaCl}_{2}$ (60:40:9) was performed according to Magnani et al. (1980) with the addition of $1 \mathrm{mg} / \mathrm{ml}$ of 
bovine serum albumin (BSA, grade VII, Sigma) to the wash buffers. An indirect method was used; plates were first incubated with monoclonal antibody $(0.3$ to $1.0 \mu \mathrm{g} /$ $\mathrm{ml}$ ) and then with ${ }^{125} \mathrm{I}$-labeled rabbit anti-mouse kappa chain antibody $\left(5 \times 10^{5} \mathrm{cpm} / \mathrm{ml}\right)$. The washed plates were air dried and exposed to XAR5 film (Kodak) at $-70^{\circ} \mathrm{C}$ with an intensifying screen (Cronex). For the visualization of gangliosides, thin layer chromatography plates were sprayed with the resorcinol reagent (Svennerholm, 1957) and heated at $110^{\circ} \mathrm{C}$ for 20 to $30 \mathrm{~min}$.

Analytical methods. Binding of monoclonal antibodies to cell lines in microtiter plate wells (Falcon) was done according to Cobbold and Waldmann (1981). An ${ }^{125} \mathrm{I}-$ labeled rabbit anti-mouse kappa chain antibody was used in these and in all other binding assays. For the ganglioside-mediated inhibition assay, solutions of gangliosides in chloroform:methanol $(2: 1)$ were added to microtiter wells and dried under vacuum. Following treatment of wells with 5\% BSA to block any nonspecific binding sites, anti-D1.1 antibody was added to the wells and allowed to bind for $1 \mathrm{hr}$ at room temperature. The supernatants were then removed from each well and added to other wells containing glutaraldehyde-fixed B49 cells. Residual antibody binding to B49 cells was then measured as described above. The trypsin sensitivity of antibody binding to $\mathrm{B} 49$ cells was assayed by treating 2 $\times 10^{6} \mathrm{~B} 49$ cells suspended in $0.2 \mathrm{ml}$ of $\mathrm{DME}$ buffered with $\quad N$-2-hydroxyethylpiperazine- $N$-2-ethanesulfonic acid (HEPES) with trypsin (Worthington) for $30 \mathrm{~min}$ at $37^{\circ} \mathrm{C}$. Cells were washed twice in HEPES-buffered DME supplemented with $5 \%$ FCS, and sequentially treated with anti-D1.1 antibody and ${ }^{125}$ I-labeled rabbit antimouse kappa chain antibody. Control cells were incubated without trypsin. To determine whether antibody binding was measured as described above. Control cells were incubated either in buffer alone or in buffer containing enzyme that had been inactivated by heating to $100^{\circ} \mathrm{C}$ for $10 \mathrm{~min}$. Sialic acid was determined by the resorcinol assay (Svennerholm, 1957). Antibody absorption with living cells was performed as described earlier were incubated in either buffer alone or in buffer containing enzyme that had been inactivated by heating to $100^{\circ}$ for $10 \mathrm{~min}$. Sialic acid was determined by the resorcinal assay (Svennerholm, 1957). Antibody absorption with living cells was performed as described earlier (Stallcup et al., 1983; the limitations of these techniques are discussed). For pronase treatment, gangliosides were dried under vaccum and resuspended by sonication in $0.1 \mathrm{M}$ Tris, pH 8.2. Pronase (Calbiochem) was added to a final concentration of $1 \mathrm{mg} / \mathrm{ml}$, and the mixture was incubated at $37^{\circ}$ for $17 \mathrm{hr}$. Gangliosides were extracted from the reaction mixture by the addition of $4 \mathrm{vol}$ of chloroform:methanol (1:1). The ganglioside containing extract was dried under $\mathrm{N}_{2}$ and resuspended in $50 \mu \mathrm{l}$ of chloroform:methanol $(2: 1)$ and spotted onto thin layer plates.

Reagents. Neuraminidase (Clostridium perfringens) was purchased from Sigma. Neuraminidase (Vibrio cholerae) was purchased from Cal-Biochem. $\mathrm{GT}_{1}, \mathrm{GD}_{1 \mathrm{a}}, \mathrm{GM}_{1}$, and bovine brain gangliosides were purchased from $\mathrm{Su}$ pelco. $\mathrm{GD}_{1 \mathrm{~b}}, \mathrm{GD}_{2}, \mathrm{GD}_{3}, \mathrm{GM}_{2}$, and $\mathrm{GM}_{3}$, and Iatro beads were kindly supplied by D. Cheresh. Glass-distilled chlo- roform and methanol were purchased from MCB. All other reagents were purchased from Sigma.

\section{Results}

We immunized mice with B49 cells and fused their spleen cells with myeloma cells as described under "Materials and Methods." Antibody D1.1 was selected for further analysis on the basis of the immunofluorescent staining pattern seen when it was tested on sections of fixed embryonic rat brain. Figure 1 shows that anti-D1.1 fluorescently labeled cells of the developing rat brain. At embryonic day 12 , the entire width of the developing telencephalon was labeled in a coarse granular fashion. Cells lying outside the CNS were not labeled with antiD1.1. At embryonic day 18, ventricular zones of the developing brain were fluorescently labeled with antiD1.1; however, cells in the mantle and marginal zones, distal to the ventricular surfaces, were not labeled with the anti-D1.1 antibody. These observations suggested that the anti-D1.1 antibody might be recognizing an antigen associated with neuroepithelial cells.

Distribution of the D1.1 antigen in the developing rat cerebellum. To explore more fully the pattern of immunoreactivity seen with anti-D1.1 antibody, we used the developing cerebellum as a model system. The cerebellar external granule layer provides a well characterized population of precursor or germinal cells. As these cells cease to divide, they migrate away from the EGL and differentiate into granule neurons and the inhibitory interneurons of the molecular layer (Altman, 1969). Figure 2 shows that the anti-D1.1 antibody immunofluorescently labeled cells of the EGL. Labeling was apparent at embryonic day 18 when the EGL begins to form. The EGL was labeled throughout the period of rapid cell proliferation as shown on postnatal day 7 (Fig. 2, $C$ and $D$ ) and on postnatal day 11 (Fig. $2, E$ and $F$ ). Beginning on about postnatal day 20 , the labeling with the anti-D1.1 antibody was no longer seen (Fig. 2, $G$ and $H$ ). This corresponds to the time when the EGL itself disappears. No cells within the adult cerebellum were fluorescently labeled with the anti-D1.1 antibody. Thus, the anti-D1.1 antibody recognizes an antigen that is expressed by cells of the cerebellar EGL as well as by cells of the ventricular layers of the developing brain.

The following absorption experiments indicate that the antigenic determinant being recognized on CNS germinal cells is also found on B49 cells. The antibody was absorbed these times with an equal volume of packed B49 cells. As shown in Figure $3 B$, this absorption completely removed the immunofluorescent staining activity when tested against sections of postnatal day 7 cerebellum. Absorption of the antibody with B35 cells, which do not bind the antibody (Table I), did not remove the immunofluorescent staining activity, thus ruling out the possibility that the antibody was nonspecifically trapped in the cell pellets used for absorption. Figure $3 D$ shows the background level of staining obtained with the fluorescein-conjugated goat anti-mouse antibody alone.

Germinal cells throughout the brain divide rapidly and can be identified histologically by $\left[{ }^{3} \mathrm{H}\right]$ thymidine autoradiography after short (2 to $3 \mathrm{hr}$ ) survival times. We used this method to determine whether the anti-D1.1- 

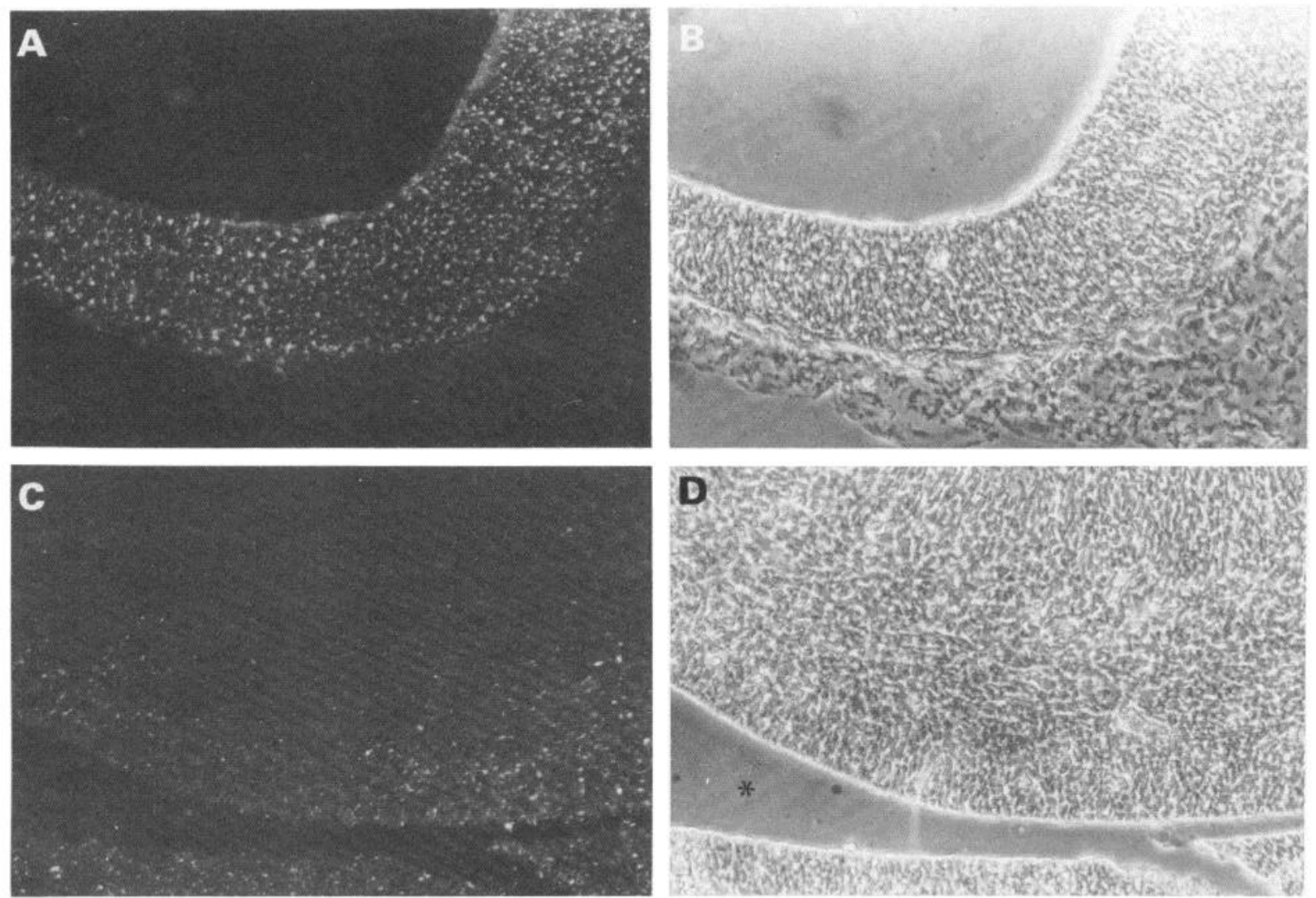

Figure 1. Immunofluorescent and phase photomicrographs of embryonic rat brain. $A$ and $B$, A horizontal section of embryonic day (ED) 12 telencephalon. $C$ and $D$, a sagittal section through the forebrain of an ED18 rat embryo. The asterisk in $D$ indicates the lumen of the lateral ventricle. $\times 150$.

labeled cells were synthesizing DNA. We injected postnatal day 7 rat pups with $\left[{ }^{3} \mathrm{H}\right]$ thymidine and processed the tissue for both autoradiography and immunoperoxidase staining as described under "Materials and Methods." Figure $4 a$ shows that following a 3 -hr survival time, cells of the EGL were labeled heavily with silver grains, indicating that many of these cells were in S phase at the time of isotope injection. The silver grain-labeled cells lie within a zone of anti-D1.1 immunoreactivity. These data suggest that the D1.1 positive cells are capable of synthesizing DNA. Because a systemic injection of $\left[{ }^{3} \mathrm{H}\right]$ thymidine results in a pulse label, the analysis of progressively longer survival times allows one to map the fate of cells that went through their final round of DNA synthesis during the pulse. In the material prepared from animals that survived $48 \mathrm{hr}$ after isotope injection (Fig. $4 b$ ), many of the cells that were heavily labeled with silver grains had migrated away from the EGL. These cells were no longer labeled with the anti-D1.1 antibody. Within $48 \mathrm{hr}$ of their final mitosis, nascent cerebellar cells have lost or biochemically altered the D1.1 antigen so that it is no longer recognized by its monoclonal antibody.

Distribution of the D1.1 antigen on cerebellar cells in vitro. We examined the distribution of the D1.1 antigen on cerebellar cells in dissociated tissue culture by the immunofluorescent staining of living cells. To characterize the D1.1 positive cells, we used the following cell type-specific markers: tetanus toxin (a probe specific for the neuronal surface; Mirsky et al., 1978), anti-glial fibrillary acidic protein (a probe for astroglial intermediate filaments; Bignami et al., 1972), and anti-galactocerebroside (a probe specific for oligodendrocytes; Raff et al., 1978). Figure 5 shows that some of the neurons and some of the astrocytes in these cultures were labeled with the anti-D1.1 antibody. Oligodendyrocytes were not fluorescently labeled with anti-D1.1. In these cultures, a small number of GFAP-negative flat cells were also stained with the anti-D1.1 antibody. These flat cells were not labeled with either an antibody against fibronectin or with the RAN-2 monoclonal antibody (Bartlett et al., 1981) (data not shown). Although the identity of the flat cells is unknown, these results suggest that they are neither fibroblasts nor meningeal cells.

The diversity of immunoreactive cell types in primary cultures of rat cerebellum was also reflected in the immunoreactivity of a panel of clonal cell lines. Table I shows that the anti-D1.1 antibody bound to only 3 of 20 cell lines tested; these are B49 cells, a line with both neuronal and glial properties, B65, a neuronal cell line, and B92, a glial cell line. Figure 6 shows the indirect radioimmune binding curves used to generate the data summarized in Table I. Although B65 cells express the D1.1 surface antigen, they apparently do so at a density lower than B49 cells. B19 cells bound the antibody at background levels; the small increase in binding at high antibody concentrations is likely due to nonspecific absorption of the antibody to the cell monolayers. Unlike 

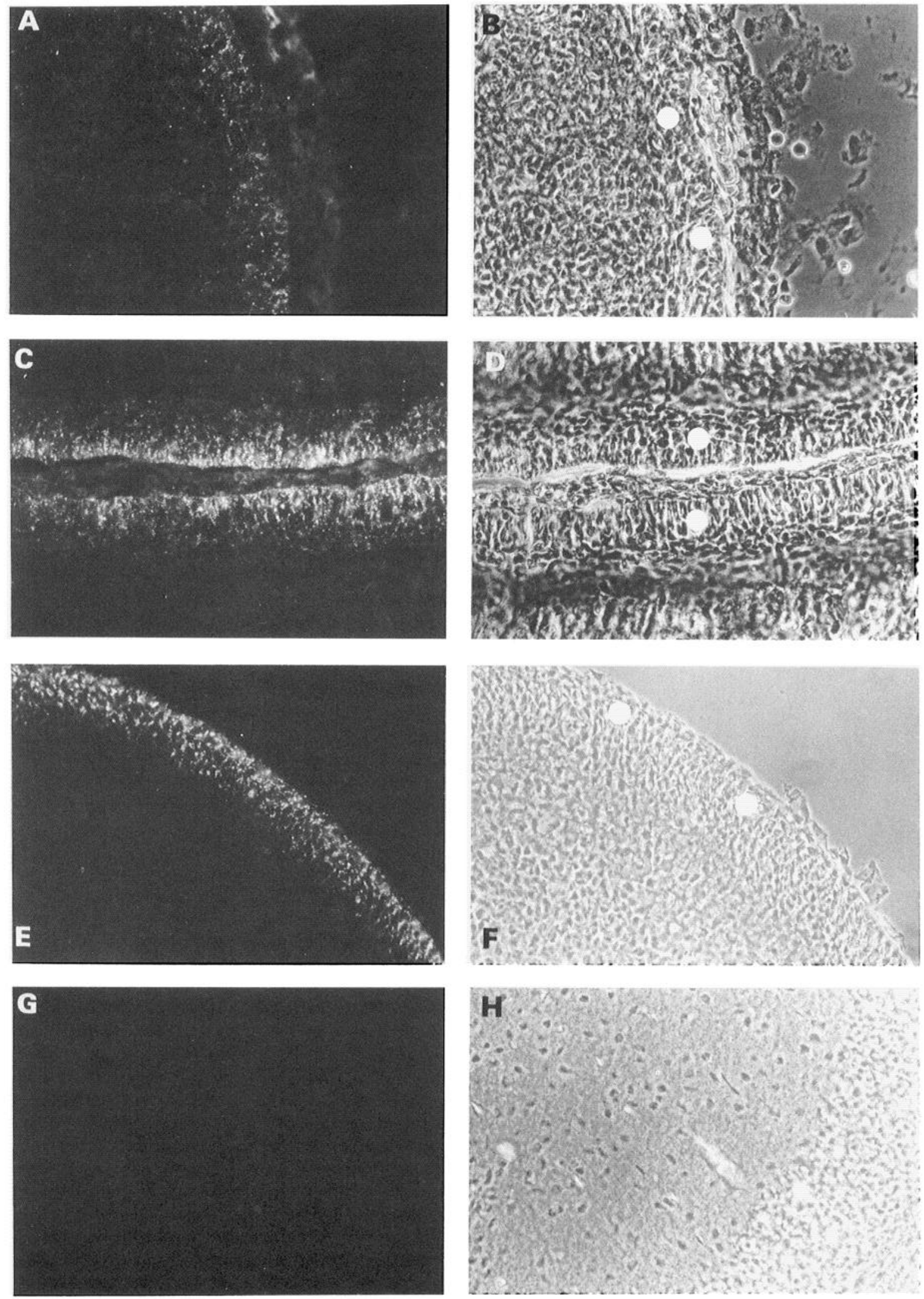

Figure 2. Immunofluorescent localization of the D1.1 antigen on sections of developing rat cerebellum. $A$ and $B, A$ horizontal section of ED18 cerebellar rudiment. $C$ and $D$, Postnatal day (PD) 7 cerebellum; $E$ and $F$, PD11; $G$ and $H$, PD22. $\times 240$. The circles in $B, D$, and $F$ denote the EGL. 

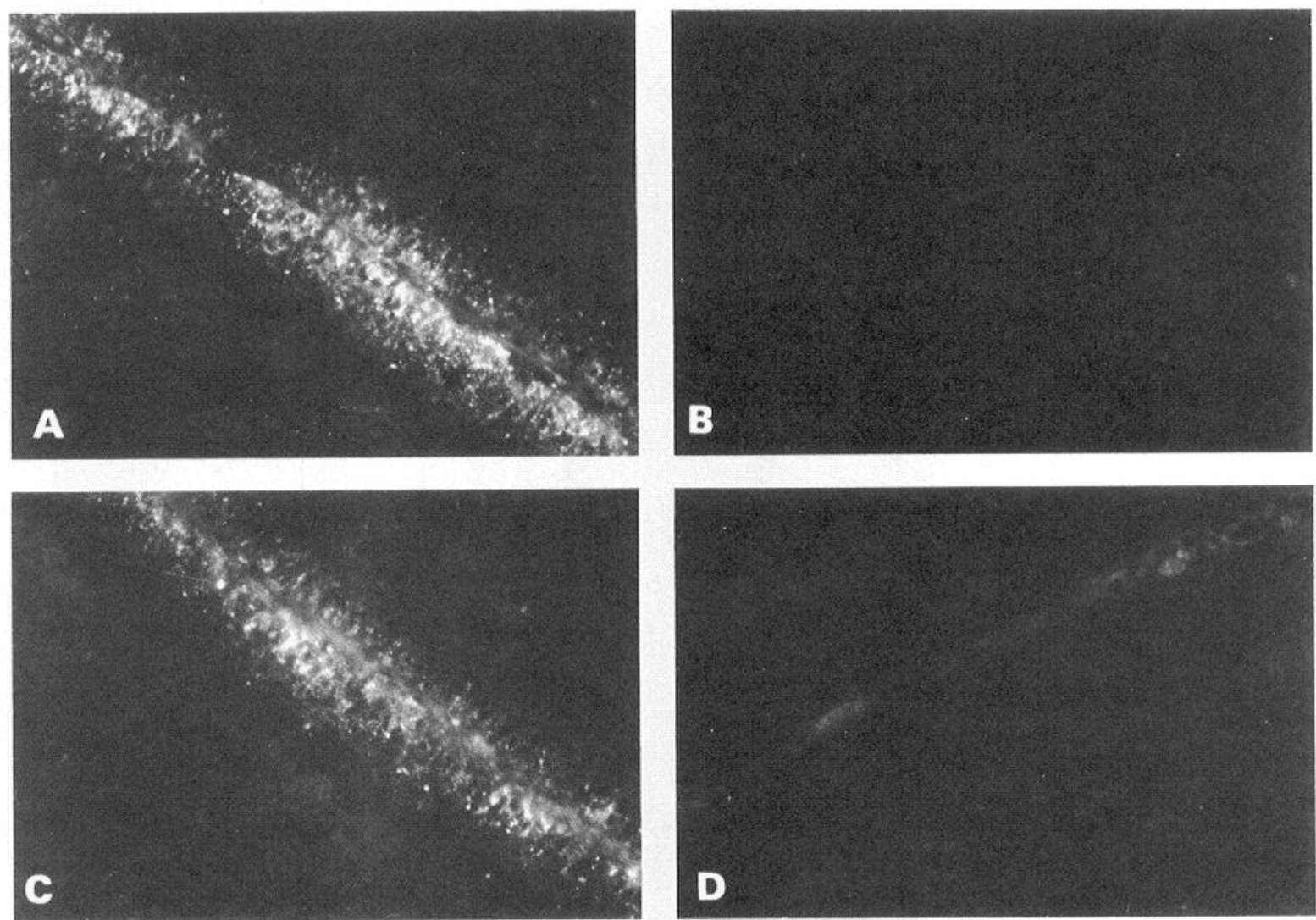

Figure 3. Specificity of the anti-D1.1 immunofluorescent staining. The anti-D1.1 antibody was absorbed with cell lines as described under "Materials and Methods" and tested for residual immunofluorescent staining activity on sections of PD 7 cerebellum. A, Unabsorbed anti-D1.1. B, Anti-D1.1 that was absorbed with B49 cells. C, Anti-D1.1 that was absorbed with B35 cells. D, A section treated with fluorescein-conjugated goat anti-mouse IgG and IgM. $\times 240$.

TABLE I

\begin{tabular}{lc}
\multicolumn{2}{c}{ Distribution of the D1.1 antigen } \\
\hline \multicolumn{1}{c}{ Cell Line } & D1.1 Antigen \\
\hline I. Nerve cell lines & - \\
B103 & - \\
B35 & - \\
ZKC & - \\
B50 & - \\
B108 & - \\
B19 & + \\
B65 & - \\
PC12 & - \\
SK-N-SH ${ }^{a}$ & - \\
TE671 & \\
II. Glial cell lines & + \\
B92 & - \\
B28 & - \\
B90 & - \\
C6 & - \\
B9 & - \\
BE11 & - \\
B111 & - \\
B49 & - \\
III. Other cell lines & \\
3T3 &
\end{tabular}

${ }^{a}$ The presence of the D1.1 antigen was determined by the indirect radioimmune binding assay described under "Materials and Methods" except in the cases marked ${ }^{\circ}$ where the antigen was determined by the immunofluorescent staining method.
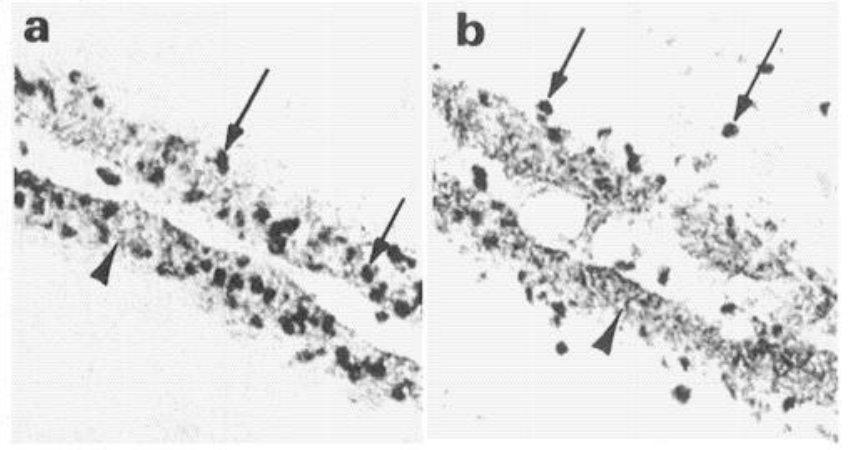

Figure 4. $\left[{ }^{3} \mathrm{H}\right]$ Thymidine autoradiography and anti-D1.1 immunoperoxidase staining of the same section. $a$, A section through the cerebellum of a PD 7 rat that had been labeled with $\left[{ }^{3} \mathrm{H}\right]$ thymidine $3 \mathrm{hr}$ prior to sacrifice. $b$, A section through the cerebellum of a PD9 rat that had been labeled with $\left[{ }^{3} \mathrm{H}\right]$ thymidine $48 \mathrm{hr}$ prior to sacrifice. The arrows indicate clusters of silver grains over the nuclei of cells, and the arrowsheads denote the granular horseradish peroxidase reaction product indicative of the presence of the D1.1 antigen. $\times 160$.

other antibodies raised against the B49 cell line, there was no clear association of cellular phenotype with the presence of the D1.1 antigen (Wilson et al., 1981). Most of the cell lines tested were derived from chemically induced tumors of the developing rat CNS (Schubert et 

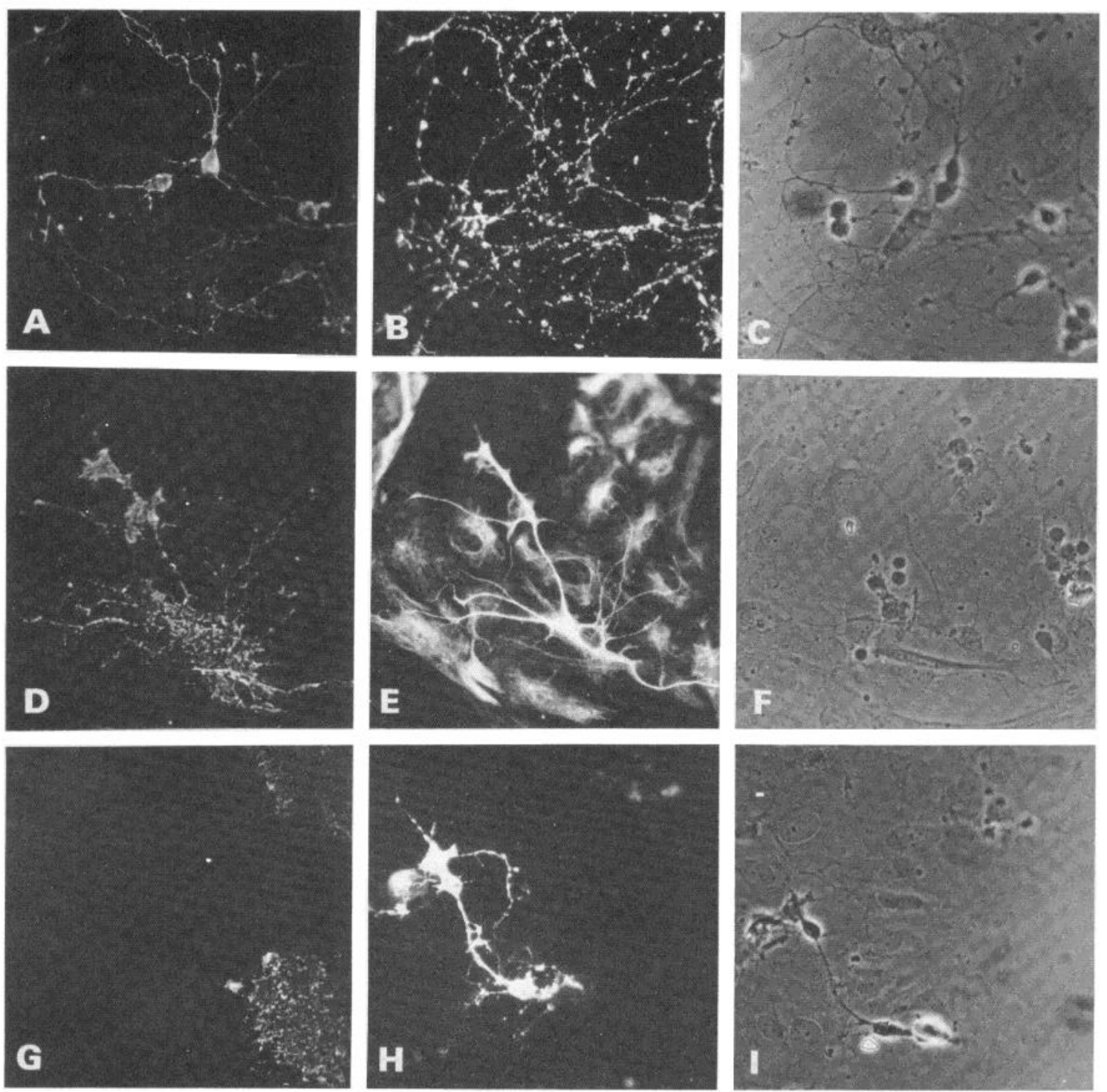

Figure 5. Double label fluorescent staining of cerebellar cells in dissociated tissue culture. $A$, Anti-D1.1 labeling of three process-bearing cells. $B$, The same field labeled with tetanus toxin, rabbit anti-toxin, and rhodamine-conjugated goat anti-rabbit IgG. $C$, Phase. $D$, Anti-D1.1 labeling of a cerebellar astrocyte. $E$, Anti-GFAP labeling of the same field following treatment in $95 \%$ ethanol, rhodamine optics. $F$, Phase. $G$, Anti-D1.1 labeling of a flat cell. $H$, Antigalactocerebroside labeling of a cerebellar oligodendrocyte in the same field. $L$ Phase.

al., 1974), so that the presence of the D1.1 antigen may indicate that the B49, B65, and B92 cell lines originated from transformed germinal cells.

When we counted the number of D1.1 positive neurons in dissociated cultures of postnatal cerebellum surviving for up to 60 days in vitro, it was apparent that the number of D1.1 positive cells declined over time. This is similar to the observations in vivo that as cells mature, they lose or biochemically alter the D1.1 antigen. However, a more trivial explanation of this observation would be that D1.1 positive cells do not survive in tissue culture. To rule out the possibility of selective cell death, it was necessary to mark cells permanently so that the same population of cells could be followed over time in tissue culture. Therefore, we labeled dividing cerebellar cells by injecting rat pups with $\left[{ }^{3} \mathrm{H}\right]$ thymidine. After either a 3 -hr or $24-\mathrm{hr}$ survival time, the pups were sacrificed, and cerebellar cultures were prepared. The cultures were fluorescently labeled with tetanus toxin and rabbit anti-tetanus toxin and with the anti-D1.1 antibody, and they were prepared for autoradiography. When the autoradiograms were developed, the cultures were counted as follows. Cells that were heavily labeled with silver grains overlying the nucleus were scored for tetanus toxin binding. This indicated whether the cells were neurons. The tetanus toxin-positive, silver grain-positive cells were then scored for anti-D1.1 binding. In this way, only neurons that went through their last round of cell division at the same time were repeatedly scored for the presence of the D1.1 antigen over the first 10 days in tissue culture. Figure 7 shows that for neurons born either 3 or $24 \mathrm{hr}$ after isotope injection, there is a decline in the number of cells ex- 
RADIOIMMUNE BINDING OF ANTI-D1.1 TO CELL LINES

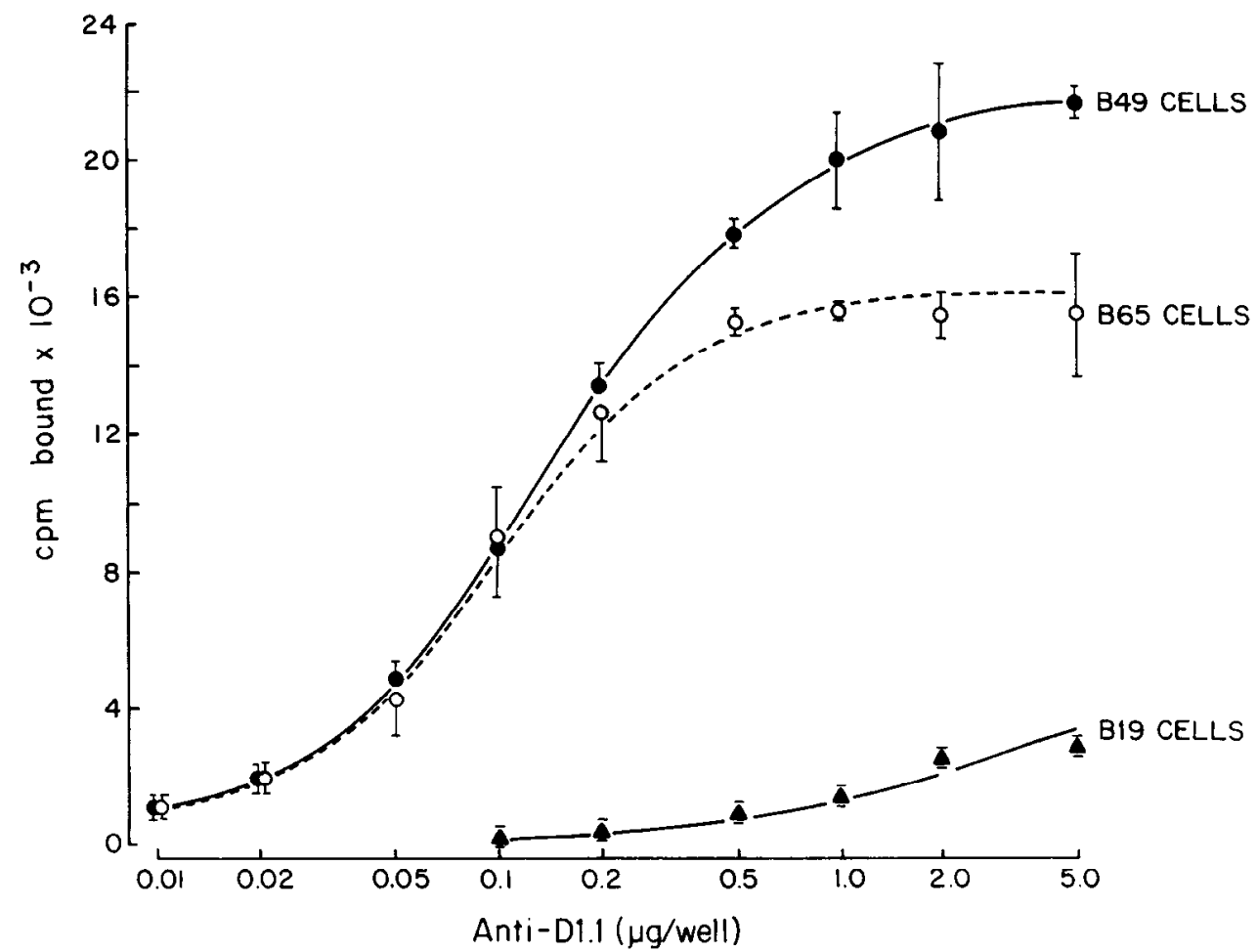

Figure 6. Indirect radioimmune binding of the anti-D1.1 antibody to monolayers of clonal cells. Cell lines seeded into poly-L-lysine-coated microtiter wells were fixed in $0.25 \%$ glutaraldehyde and processed for indirect radioimmune binding as described under "Materials and Methods."

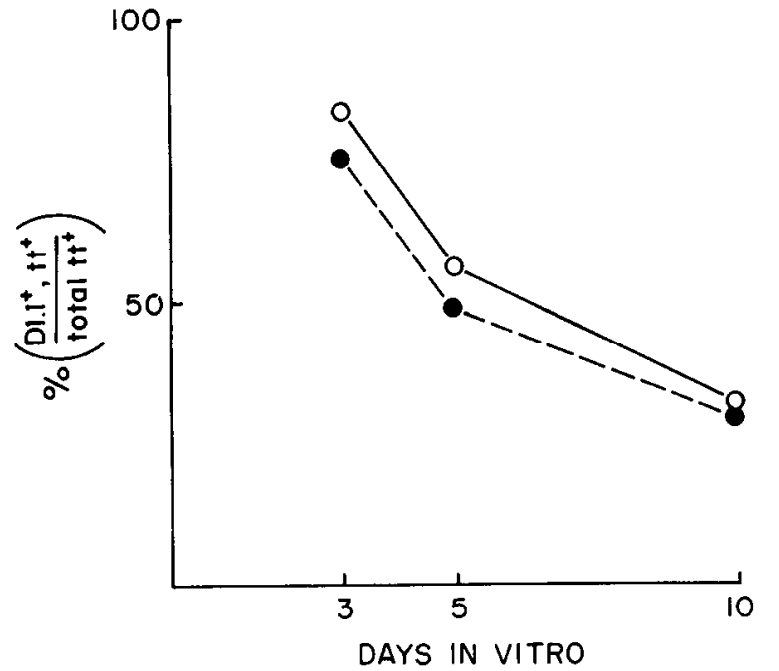

Figure 7. The progressive loss of the D1.1 antigen on cerebellar neurons in dissociated tissue culture. $\left[{ }^{3} \mathrm{H}\right]$ Thymidinelabeled cerebellar cells were fluorescently labeled with tetanus toxin and anti-D1.1 and processed for autoradiography as described under "Materials and Methods." Data are presented as the percentage of the silver grain-labeled neurons (i.e., tetanus toxin $(t t)$-positive cells) that are also labeled with anti-D1.1 as a function of days in vitro. Open circles, 3 -hr survival after $\left[{ }^{3} \mathrm{H}\right]$ thymidine injection. Solid circles, $24-\mathrm{hr}$ survival.

pressing the D1.1 antigen over time in vitro. Thus, neuronal maturation, either in vivo or in vitro, results in a loss or chemical modification of the D1.1 antigen.

Identification of the D1.1 antigen. The above results
TABLE II

Enzyme sensitivity of anti-DI.1 binding to $B 49$ cells

\begin{tabular}{lc}
\hline \multicolumn{1}{c}{ Treatment } & \% of Control \\
\hline $\mathrm{A}^{a}$ None & 100 \\
$0.05 \%$ trypsin & 137 \\
$0.1 \%$ trypsin & 133 \\
$\mathrm{~B}^{b}$ & \\
None & 100 \\
Neuraminidase 0.05 unit & 36 \\
$\quad$ (C. perfringens) & \\
Neuraminidase 0.1 unit & 20 \\
Neuraminidase 0.1 unit & 92 \\
$\quad$ heat inactivated & \\
Neuraminidase 0.05 unit & 31 \\
$\quad$ (V. cholerae) & \\
\hline Ba cells $2 \times 10 \%$ &
\end{tabular}

${ }^{u}$ B49 cells $\left(2 \times 10^{6}\right)$ suspended in HEPES-buffered DME, were treated with the indicated concentration of trypsin for $30 \mathrm{~min}$ at $37^{\circ}$. Cells were washed twice in HEPES-buffered DME $+5 \%$ FCS and treated with anti-D1.1 $(2 \mu \mathrm{g})$ and $\left[{ }^{125} \mathrm{I}\right] \mathrm{rabbit}$ anti-mouse antibody as described under "Materials and Methods." $100 \%=6000 \mathrm{cpm}$ bound.

${ }^{6} \mathrm{~B} 49$ cells $\left(2 \times 10^{5}\right)$ bound to microtiter plates were treated with the indicated concentration of enzymes at $\mathrm{pH} 6.0$ for $30 \mathrm{~min}$ at $37^{\circ} \mathrm{C}$. Following the incubation the plates were washed, fixed, blocked, and treated with anti-D1.1 $(0.3 \mu \mathrm{g} / \mathrm{ml})$ and $\left[{ }^{125} \mathrm{I}\right] \mathrm{rabbit}$ anti-mouse antibody as described under "Materials and Methods." $100 \%=11,000 \mathrm{cpm}$ bound.

suggest that the molecule(s) being recognized by the antiD1.1 antibody may be a specific marker for the surfaces of neuroepithelial or germinal cells. To learn about its possible functions at the cell surface, it is necessary to 
characterize the antigen(s) biochemically. Generally, there are three classes of molecules associated with the cell surface: (1) proteins, including glycoproteins; (2) proteoglycans; and (3) lipids, including phospholipids, neutral glycolipids, and gangliosides. The anti-D1.1 antibody did not precipitate any components from lysates of B49 cells that had been surface labeled with ${ }^{125} \mathrm{I}$, suggesting that the antigen is not a cell surface protein or glycoprotein. Therefore, we used the indirect radioim-

\section{TABLE III}

Ganglioside inhibition of anti-D1.1 binding to B49 cells

Gangliosides bound to microtiter plates were treated with anti-D1.1 $(0.26 \mu \mathrm{g})$ for $1 \mathrm{hr}$ at room temperature. The supernatant was then removed and tested for binding activity on fixed B49 cells in microtiter plates as described under "Materials and Methods." Percentage inhibition $=\frac{\text { control }- \text { experimental }}{\text { control }} \times 100.0$ inhibition $=5500 \mathrm{cpm}$ bound. LBSA = bound sialic acid.

\begin{tabular}{llc}
\hline & & Inhibition \\
\hline & & $\%$ \\
B49 gangliosides & $1 \mu \mathrm{g} \mathrm{LBSA}$ & 35 \\
& $2 \mu \mathrm{g}$ & 61 \\
B19 gangliosides & $1 \mu \mathrm{g}$ & 0 \\
& $2 \mu \mathrm{g}$ & 0 \\
Mixed bovine brain & $15 \mu \mathrm{g}$ & 0 \\
gangliosides & $30 \mu \mathrm{g}$ & 0 \\
\hline
\end{tabular}

mune binding assay described under "Materials and Methods" to gain information about the biochemical nature of the antigen being recognized by the antibody. Table II shows that antibody binding to B49 cells was inhibited by treating the cells with neuraminidase; this enzyme cleaves terminal sialic acid residues from glycoproteins, gangliosides, and acidic glycolipids. Antibody binding, while sensitive to neuraminidase treatment, was insensitive to mild trypsin treatment. The increase in binding seen following trypsin treatment may reflect the unmasking of cryptic antigenic sites.

The results shown in Table II provide evidence that the anti-D1.1 antibody is recognizing a trypsin-insensitive, sialic acid-containing molecule. Gangliosides, as well as some glycoproteins, comprise such a class of cell surface molecules. We tested the possibility that the D1.1 antigen might be a ganglioside by preparing a total ganglioside fraction from clonal cell lines and testing these extracts for their ability to inhibit antibody binding to B49 cells. Table III shows that gangliosides prepared from B49 cells inhibit antibody binding. As predicted from both the radioimmune binding data and the immunofluorescence, gangliosides prepared from B19 cells or from adult bovine brain did not inhibit antibody binding to B49 cells. We used an immunoautoradiographic technique originally developed by Magnani et al. (1980) to identify the component of these extracts responsible for antibody binding. Figure 8 shows that the
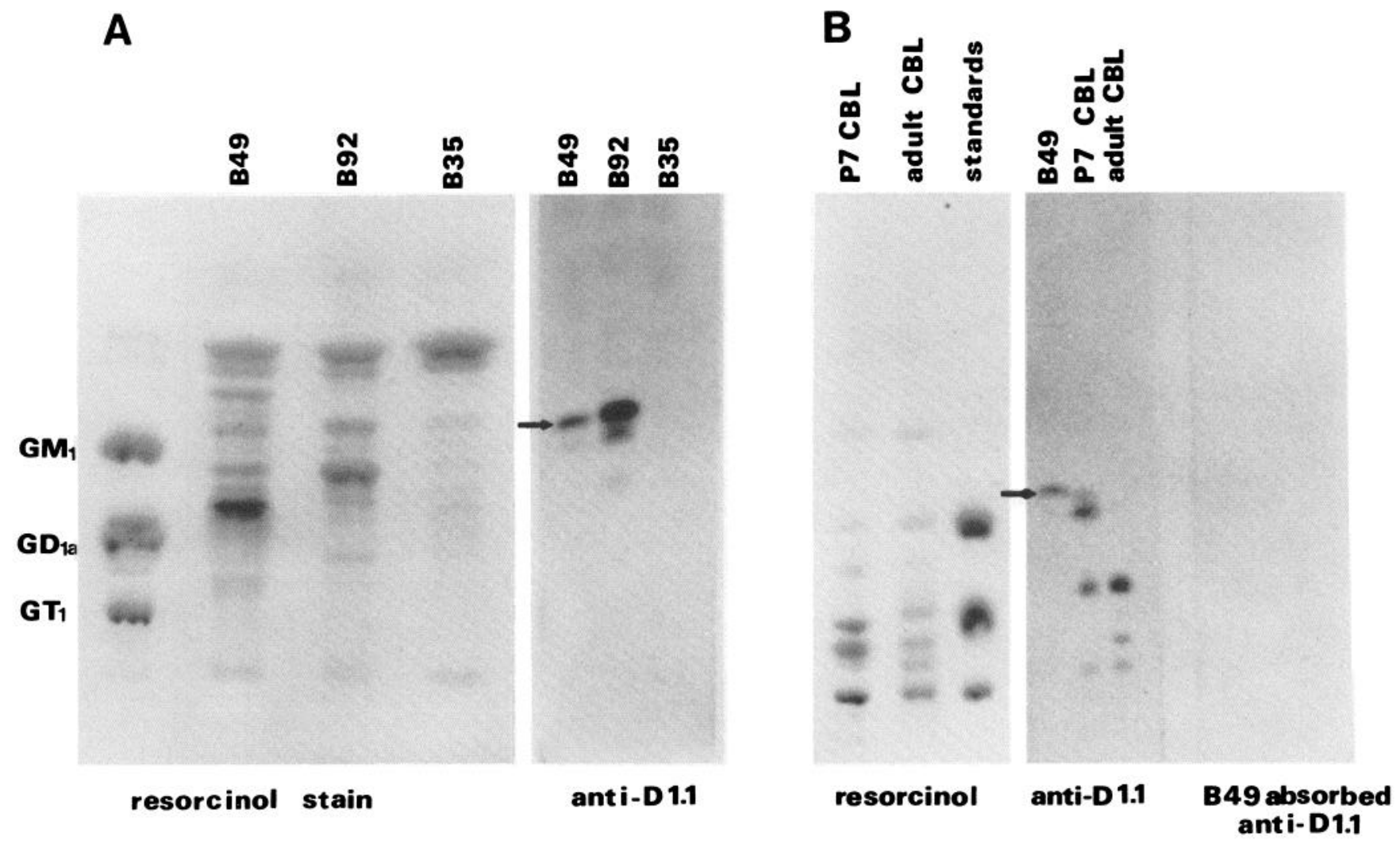

Figure 8. The immunoautoradiographic identification of the D1.1 antigen. Gangliosides were prepared from the indicated cell lines and tissues and separated by chromatography on plastic backed high performance thin layer chromatography plates as described under "Materials and Methods." The plates were subsequently cut into strips. One strip was stained with the resorcinol reagent, and a parallel sample from the same plate was treated with anti-D1.1 and a ${ }^{125} \mathrm{I}$-labeled rabbit anti-mouse kappa chain antibody as described by Magnani et al. (1980). A, Cell lines. B, Cerebellar tissue. The standards from bottom to top are $\mathrm{GT}_{1}$, $\mathrm{GD}_{1 \mathrm{a}}$, and $\mathrm{GM}_{1}$. The arrows in $A$ and $B$ indicate the mobility of the major D1.1 antigen. 
antibody recognized a ganglioside band with a mobility slightly greater than that of the $\mathrm{GM}_{1}$ ganglioside. This component was present in ganglioside extracts prepared from cell lines that bind the antibody and was absent in extracts from cell lines that do not bind the antibody. Furthermore, a band with a similar mobility on thin layer chromatograms is present in gangliosides prepared from postnatal day 7 cerebellum and absent from adult cerebellum. Absorption oi anti-D1.1 with intact B49 cells completely removed the ability of the antibody to bind to any gangliosides separated on thin layer chromatograms. The antibody recognized several more slowly migrating bands in thin layer chromatograms of developing and adult cerebellar gangliosides. The relationship of the single antigenic component found on B49 cells to those found in adult cerebellum is unclear. The adult cerebellar bands may be molecules with structural similarities to the B49 component. Because there was no detectable immunofluorescent staining of adult cerebellar tissue with anti-D1.1, these components may be present in low densities at the cell surface. Alternatively, the molecules represented by these bands may be cryptic at the cell surface.

The lipid fractions used here are likely to contain traces of both neutral and acidic glycolipids as well as gangliosides. To rule out the possibility that these trace contaminants were responsible for the antigenic activity of the extracts, we purified B49 gangliosides by ion exchange chromatography on DEAE-Sephadex to remove any uncharged and zwitterionic lipids and by latro bead column chromatography to remove any contaminating acidic glycolipids and sulfatides. This highly purified ganglioside fraction contained a component that was recognized by the anti-D1.1 antibody and that comigrated with the component present in the unpurified ganglioside fraction. The antibody-binding component was not destroyed by pronase treatment (data not shown). We also tested the D1.1 antibody against purified ganglioside standards $\left(\mathrm{GT}_{1}, \mathrm{GD}_{1 \mathrm{a}}, \mathrm{GD}_{1 \mathrm{~b}}, \mathrm{GD}_{2}, \mathrm{GD}_{3}\right.$, $\mathrm{GM}_{1}, \mathrm{GM}_{2}$, and $\mathrm{GM}_{3}$ ) and against commercially available mixed bovine brain gangliosides. No immunoreactive bands were seen on these thin layer chromatograms (data not shown), suggesting that the D1.1 ganglioside may be a unique molecular species transiently expressed during neurogenesis.

\section{Discussion}

Gangliosides are a class of acidic glycosphingolipids that are found at high concentrations within the CNS. Most of the gangliosides found in brain are associated with the plasma membrane (Ledeen, 1978); their branched carbohydrate structures have led to the suggestion that gangliosides participate in cell-cell interactions, especially during development (Fishman and Brady, 1976; Hakomori, 1981). The results presented here demonstrate that a unique ganglioside antigen is expressed on the surfaces of CNS germinal cells. As neurons and astrocytes mature, either in vivo or in vitro, this ganglioside antigen is either lost or biochemically modified so that it is no longer recognized by its monoclonal antibody. One aspect of the early differentiation of both neurons and glial cells is the expression and subsequent loss of the D1.1 ganglioside.
We have presented both direct and indirect evidence that the determinant recognized by the anti-D1.1 antibody is carried on a ganglioside. First, antibody binding to living cells is sensitive to neuraminidase treatment and is insensitive to trypsin. It is likely that a sialic acid residue is part of the epitope recognized by the antibody. Second, preparations of gangliosides from the appropriate cell lines can inhibit antibody binding to B49 cells, suggesting that the antigenic site is a component of this lipid fraction. Third, immunoautoradiographic staining of thin layer chromatograms demonstrates that a single component from B49 cells binds the antibody. The presence of this antigenic ganglioside, which has a mobility on thin layer chromatograms similar but not identical to that of $\mathrm{GM}_{2}$, correlates with the ability of the source of the lipids, either cell lines or tissues, to bind the antibody. Thus, the D1.1 positive B49 cells and B92 ${ }^{3}$ cells express this antigen, whereas the D1.1 negative B35 cells, a neuronal cell line, do not. Similarly, a component that co-migrates with the antigen found on B49 cells is present in postnatal day 7 cerebellum but absent in adult cerebellum. Several more slowly migrating gangliosides of postnatal and adult cerebellum are recognized by the anti-D1.1 antibody. The carbohydrate structures of these gangliosides are likely to bear enough resemblance to the structure of the B49 component to be recognized by the antibody. In this regard, the anti-D1.1 antibody may be similar to antibodies against the SSEA-1 antigen which recognize a Gal $\beta 1 \rightarrow 4$ [Fuc $\alpha 1 \rightarrow 3$ ] GlcNac carbohydrate structure that can be carried on several glycolipid core structures (Gooi et al., 1981; Kannogi et al., 1982).

Although the D1.1 antigen has a mobility on thin layer chromatographic plates similar to that of the $\mathrm{GM}_{2}$ gangliosides, it is unlikely that the D1.1 antigen is $\mathrm{GM}_{2}$ for the following reasons. The antibody does not stain $\mathrm{GM}_{2}$ when this ganglioside is subjected to thin layer chromatography and subsequent antibody treatment (data not shown), and the antibody does not recognize any components of commercially available bovine brain gangliosides which are known to contain $\mathrm{GM}_{2}$. In view of the unique distribution of the D1.1 antigen during neuronal development, it will be of interest to determine its structure and carbohydrate composition.

By virtue of its restriction to germinal cells within the CNS, the D1.1 antigen may prove to be a useful marker for the cell lineage that gives rise to the mammalian CNS. We have analyzed the expression of the D1.1 antigen in detail only in the postnatal cerebellum. Here cells of the external granule layer, but no other cells, are fluorescently labeled with anti-D1.1. $\left[{ }^{3} \mathrm{H}\right]$ Thymidine autoradiography demonstrated that the D1.1 antigen is localized to an area that contains dividing cells. Furthermore, when dissociated cell cultures were prepared from animals that had been labeled with $\left[{ }^{3} \mathrm{H}\right]$ thymidine $3 \mathrm{hr}$ prior to sacrifice in order to label dividing cells, over $80 \%$ of the thymidine-labeled neurons bound the antibody after 3 days in culture. These observations suggest that D1.1 positive germinal cells synthesize DNA. We estimate that within $48 \mathrm{hr}$ after their final mitosis, newly

\footnotetext{
${ }^{3}$ The antigenic components found on B92 cells and postnatal day 7 cerebellum often appear as doublets, reflecting the fact that the polar head group can be carried on different length ceramide moieties.
} 
born cerebellar cells lose the ability to the labeled with anti-D1.1. The time course for loss of antigen is longer on cells in tissue culture ( $T_{1 / 2}=2.5$ to 3 days), most likely reflecting the fact that the tissue culture milieu does not provide all of the factors and interactions that are responsible for antigen loss in vivo. This same pattern of immunoreactivity, that is, fluorescent labeling of cells of the ventricular zones but no labeling of cells of the mantle and marginal zones, was consistently seen throughout the developing brain. In the postnatal material analyzed here, the subependymal zone, an area containing dividing germinal cells that can give rise to glial cells and neurons (Smart, 1963), was also labeled with anti-D1.1. As in the case of the cerebellum, cells that have migrated away from the subependymal zone were not labeled with anti-D1.1.

These results demonstrate that the expression of the D1.1 antigen is regulated during neuronal and glial differentiation. Both the absolute amount of gangliosides and the distribution of sialic acid among different species of gangliosides changes during neural development (Yavin and Yavin, 1979; Irwin and Irwin, 1982; Rosner, 1982) or accompanying transformation of tissue culture cells (Brady and Fishman, 1974). In the case of livers from rats fed the carcinogen $N$-2-acetylaminofluorene, the accumulation of $\alpha$-fucosyl-GM $\mathrm{GM}_{1}$ appears to be due to the induction of an $\alpha$-fucosyltransferase activity (Holmes and Hakomori, 1983). Changes in glycosyltransferase activities during neurogenesis could be responsible for the expression and subsequent loss of the D1.1 antigen. However, it must be emphasized that the biosynthesis of gangliosides is complex and can be affected by the activities of multienzyme complexes (Fishman and Brady, 1976) and by the presence of activator proteins ( $\mathrm{Li}$ et al., 1980). Furthermore, several groups have recently demonstrated glycosyltransferase activities associated with the neuronal cell surface (Pierce, 1982; Matsui et al., 1983). These observations suggest that the D1.1 ganglioside might serve as a substrate for extracellular enzymes. In this way, cellular migration out of the ventricular zones and into areas of the nervous system containing differentiated neurons and glial cells may expose the D1.1 ganglioside to an enzymatic activity which modifies the carbohydrate structure of the molecule in a manner such that it is no longer recognized by its monoclonal antibody. Because the resulting loss of antigenicity is one step in the processes that lead to the functional and biochemical maturation of the nervous system, it will be important to determine the mechanisms involved here.

Several other laboratories have used immunological approaches to identify cell surface molecules of the developing cerebellum. Willinger and Schachner (1980) have shown that granule neurons express the $\mathrm{GM}_{1}$ ganglioside as they begin to migrate away from the EGL. DeBaeque et al. (1976) have shown that $\mathrm{GM}_{1}$ is a marker for granule cell somata in the adult rat cerebellum. In contrast to the D1.1 ganglioside, which marks a proliferative stage of cerebellar development, the $\mathrm{GM}_{1}$ ganglioside appears as cells cease dividing and begin to differentiate. The thy 1.1 glycoprotein antigen appears on some cerebellar neurons (presumptive granule neurons) only after 2 to 4 weeks in tissue culture (Fields et al., 1982). Taken together, these cell surface antigens mark or define different stages in the development of cerebellar granule cells: an early or proliferative stage marked by $\mathrm{D} 1.1$, an intermediate stage marked by the initial appearance of $\mathrm{GM}_{1}$, and a late or fully differentiated stage marked by both $\mathrm{GM}_{1}$ and thy 1.1. The analysis of systematic changes in cell surface properties as demonstrated here provides a means of understanding the final consequences of changing gene expression during neuronal development.

\section{References}

Altman, J. (1969) Autoradiographic and histological studies of postnatal neurogenesis. III Dating the time of production and onset of differentiation of cerehellar microneurons in rats. J. Comp. Neurol. 136: 269-294.

Altman, J. (1972) Postnatal development of the cerebellar cortex in the rat. I. The external germinal layer and the transitional molecular layer. J. Comp. Neurol. 145: 353-398.

Altman, J., and S. A. Bayer (1978) Prenatal development of the cerebellar system in the rat. I. Cytogenesis and histogenesis of the deep nuclei and the cortex of the cerebellum. J. Comp. Neurol. 179: 23-48.

Bartlett, P. F., M. D. Noble, R. M. Pruss, M. C. Raff, S. Rattray, and C. A. Williams (1981) Rat neural antigen-2 (RAN-2): A cell surface antigen on astrocytes, ependymal cells, Müller cells and leptomeninges defined by a monoclonal antibody. Brain Res. 204: 339-351.

Bignami, A., L. Eng, D. Dahl, and C. Uyeda (1972) Localization of the glial fibrillary acidic protein in astrocytes by immunofluorescence. Brain Res. 43: 429-435.

Brady, R. O., and P. H. Fishman (1974) Biosynthesis of glycolipids in virus-transformed cells. Biochim. Biophys. Acta 355: 121-148.

Cobbold, S. P., and H. Waldmann (1981) A rapid solid-phase enzyme linked binding assay for screening monoclonal antibodies to cell surface antigens. J. Immunol. Methods 44: 125133.

Dahms, N. M., and R. L. Schnarr (1983) Ganglioside composition is regulated during differentiation in the neuroblastoma $\times$ glioma hybrid cell line NG108-15. J. Neurosci. 3: 806-817.

DeBaeque, C., A. B. Johnson, M. Naiki, G. Schwarting, and D. M. Marcus (1976) Ganglioside localization in cerebellar cortex: An immunoperoxidase study with antibody to $\mathrm{GM}_{1}$ ganglioside. Brain Res. 114: 117-122.

Fields, K. L., D. N. Currie, and G. R. Dutton (1982) Development of thy-1 antigen on cerebellar neurons in culture. J. Neurosci. 2: 663-673.

Fishman, P. H., and R. O. Brady (1976) Biosynthesis and function of gangliosides. Science 194: 906-915.

Folch, J., M. Lees, and G. H. Sloan Stanley (1957) A simple method for the isolation and purification of total lipids from animal tissues. J. Biol. Chem. 226: 497-509.

Gooi, H. C., T. Feizi, A. Kapadia, B. B. Knowles, D. Solter, and M. J. Evans (1981) Stage-specific embryonic antigen involves $\alpha 1 \rightarrow 3$ fucosylated type 2 blood group chains. Nature 292: $156-158$.

Gottlieb, D. I., and L. Glaser (1980) Cellular recognition during neural development. Annu. Rev. Neurosci. 3: 303-318.

Hakomori, S. I. (1981) Glycosphingolipids in cellular interactions, differentiation and oncogenesis. Annu. Rev. Biochem. 50: $733-764$.

Hartmann, B. K. (1973) Immunofluorescence of dopamine- $\beta$ hydroxylase. Application of improved methodology to the localization of the peripheral and central noradrenergic nervous system. J. Histochem. Cytochem. 21: 312-332.

Holmes, E. H., and S. I. Hakomori (1983) Enzymatic basis for changes in fucoganglioside during chemical carcinogenesis. J. Biol. Chem. 258: 3706-3713. 
Irwin, L. N., and C. C. Irwin (1982) Developmental changes and regional variation in the ganglioside composition of the rat hippocampus. Dev. Brain Res. 4: 481-485.

Jacobson, M. (1978) Developmental Neurobiology, Ed. 2, Holt, Rinehart and Winston, Inc., New York.

Kannogi, R., E. Nudelman, S. B. Levery, and S. I. Hakomori (1982) A series of human erythrocyte glycosphingolipids reacting to the monoclonal antibody directed to developmentally regulated antigen, SSEA-1. J. Biol. Chem. 257: 14865-14874.

Kearney, J. F., A. Radbruch, B. Leisegang, and K. Rajewsky (1979) A new mouse myeloma cell line that has lost immunoglobulin expression but permits the construction of antibody - secreting hybrid cell lines. J. Immunol. 123: 15481550.

Kohler, G., and C. Milestein (1975) Continuous cultures of fused cells secreting antibody of predefined specificity. $\mathrm{Na}$ ture 265: $495-497$.

Ledeen, R. W. (1978) Ganglioside structure and distribution: Are they localized at the nerve ending? J. Supramol. Struct. 8: 1-17.

Ledeen, R. W., and R. K. Yu (1978) Methods for isolation and analysis of gangliosides. In Research Methods in Neurochemistry, N. Marks and R. Rodnight, eds., Vol. 4, pp. 371-410, Plenum Press, New York.

Li, Y. T., M. J. King, and S. C. Li (1980) Enzymatic degradation of gangliosides. In Structure and Function of Gangliosides, L. Svennerholm, P. Mandel, H. Dreyfus, and P. F. Urban, eds., pp. 93-104, Plenum Press, New York.

Magnani, J. L., D. G. Smith, and V. Ginsburg (1980) Detection of gangliosides that bind cholera toxin: Direct binding of ${ }^{125} \mathrm{I}$ labeled toxin to thin-layer chromatograms. Anal. Biochem. 109: 399-402.

Matsui, Y., D. Lomard, B. Hoflack, S. Harth, R. Massarelli, P. Mandel, and H. Dreyfus (1983) Ectoglycosyltransferase activities at the surface of cultured neurons. Biochem. Biophys. Res. Commun. 113: 446-453.

Mirsky, R., L. Wendon, P. Black, C. Stolkin, and D. Bray (1978) Tetanus toxin: $\Lambda$ ccll surface marker for neurons in culture. Brain Res. 148: 251-259.

Momoi, T., S. Ando, and Y. Nagai (1976) High resolution preparative column chromatographic system for gangliosides using DEAE-Sephadex and a new porous silica, latrobeads. Biochim. Biophys. Acta 441: 488-497.

Pierce, M. (1982) Quantification of ganglioside $\mathrm{GM}_{1}$ synthetase activity on intact chick neural retina cells. J. Cell Biol. 93: 76-81.

Raff, M., R. Mirsky, K. Fields, R. Lisak, S. Dorfman, D. Silberberg, N. Gregson, S. Liebowitz, and M. Kennedy (1978) Galactocerebroside: A specific cell surface antigen marker for oligodendrocytes in culture. Nature 274: 813-816.

Rosner, H. (1982) Ganglioside changes in the chicken optic lobe as biochemical indicators of brain development and maturation. Brain Res. 236: 49-61.

Schubert, D., S. Heinemann, W. Carlisle, H. Tarikas, B. Kimes, J. Patrick, J. H. Steinbach, W. Culp, and B. L. Brandt (1974) Clonal cell lines from the rat central nervous system. Nature 249: 224-227.

Smart, I. (1963) The subependymal layer of the mouse brain and its cell production as shown by radiography after thymidine ${ }^{3} \mathrm{H}$ injection. J. Comp. Neurol. 116: 325-347.

Stallcup, W. B. (1981) The NG2 antigen, a putative lineage marker: Immunofluorescent localization in primary cultures of rat brain. Dev. Biol. 83: 154-165.

Stallcup, W. B., and M. Cohn (1976) Correlation of surface antigens and cell types in cloned cell lines from the rat central nervous system. Exp. Cell Res. 98: 285-297.

Stallcup, W. B., L. S. Arner, and J. M. Levine (1983) An antiserum against the $\mathrm{PC} 12$ cell line defines cell surface antigens specific for neurons and Schwann cells. J. Neurosci. 3: $53-68$.

Svennerholm, L. (1957) Quantitative estimation of sialic acids II. A colorimetric resorcinol-hydrochloride acid method. Biochim. Biophys. Acta 24: 604-611.

Willinger, M., and M. Schachner (1980) $\mathrm{GM}_{1}$ ganglioside as a marker for neuronal differentiation in mouse cerebellum. Dev. Biol. 74: 101-117.

Wilson, S., E. E. Baetge, and W. B. Stallcup (1981) Antisera specific for cell lines with mixed neuronal and glial properties. Dev. Biol. 83: 146-153.

Yavin, E., and Z. Yavin (1979) Ganglioside profiles during neural tissue development. Dev. Neurosci. 2: 25-37. 